He was not married. $\mathrm{V}-\ldots$, who never maried, has not had it, nor D-nor $\mathrm{H}-$, nor their families. The disease in every case developed when the subjects of it were in their "teens." In the patient's father's case the attacks generally came on in the night, most frequently on Sunday night, the day's rest apparen $1 \mathrm{ly}$ predisposing to the attack. He had his first attack about the age of fifteen years. Cold and dampness seemed to have been exciting causes. He seldom had any premonition of an attack, but would wake up quite helpless and remain so for forty-eight hours, or if the attack was severe for three days. 'The head and neck were seldom affected. Daring the first attacks he had at times scme difficulty in breathing. At first the attacks came on every year, generally in the spring, but of late only once in three or four years, but they were as severe as ever-even more so.

I was led to record the above family history from reading an epitomised account in a recent number of the $B$ ritis Medical Journal of an interesting and important article which was published in the Deutsche Zeitschrift für Nerven heilkunde by Dr. Goldflam. Five years ago he communicated some particulars of a family of eleven who suffered from occasional complete paralysis of all four extremities. $\mathrm{He}$ has since had the opportunity of carefully and continuously observing two of the members of the family. 'T'he condition affected the young people of the family, and showed itself in complete flaccid paralysis affecting the limbs and the trunk, and was characterised by loss or diminution of reflexes and of mechanical and electrical excitability of muscles. The muscles which were hypertrophied showed but little strength, and the examination of freshly excised portions showed that the fibres were unusually large, that the primitive bundles were wasted, and that there was vacuolation in them. In his first communication Dr. Goldflam hazarded the guess that the disease perhaps depended upon some toxic substance acting upon the muscles and their nerve-ending so as to influence and disturb them. This hypothesis receives a certain measure of support from the fact that a ptomainelike substance is present in the urine of the patients and that a fairly constant condition of leucocytosis is also present. Possibly the poison exerts an influence on the muscles that have undergone some change in structure which renders them more susceptible to the intluence of the substance. No doubt an analogy exists between such cases and those of Thomsen's disease.

Buffalo, N.Y., U.S.A.

\section{SPRAINS OF THE JOINTS, WITH PAR- TICULAR REFERENCE TO SPRAINS OF THE ANKLE.}

BY WILFRID B. WARDE, M.B., L.R.C.P.LOAD., M.R.C.S. ENG

DURING the past few years I have had unusual oppor tunities for studying severe sprains of joints, and more particularly of the ankle joint. At one time I had six cases of sprained ankle under my care in rapid succession. The observation of these and other cases and a contrast of various modes of treatment led me to certain conclusions which have had a most satisfactory result as far as my own practice is concerned.

If cooling lotions are used or if no special treatment be adopted a sprain passes through the following stages (1) the joint swells and is very painful; (2) the pain and swelling during the next two or three days are increased by inflammation; (3) usually the joint is distended with synovial fluid; (4) the swelling slowly disappears; (5) considerable stiffness is felt which is slow in disappearing; and (6) there is great tendency to relapse. To one who has tried this kind of treatment and then tried the effects of pressure the contrast is most marked. Pressure, to act most efficiently, must be uniform and should be applied as early as possible in order to check the $f$ ow of blood from the injured vessels, which appears to be the cause of the early swelling of the joint. There is nothing better for the purpose than the starched bandage with a good thick layer of wool to completely envelop the joint. The effect of such treatment is as startling as it is satisfactory. The pain is immediately lessened, the swelling is arrested, the subsequent improvement is far more rapid, and there is less tendency to relapse.
Uniform pressure acts mainly by lessening extravasation, and certainly the other results follow.

But pressure acts in another way. The more swelling there is the greater will be the interference with all movements of the joint, and further, the greater the distension and the longer it continues the more relaxed will be the tissues, and so there will be a greater tendency to relapses. If pressure has been well applied from the beginning it is astonishing how little real stiffness, as opposed to mere weakness, there is, and it is quite easy to keep the joint from becoming distended when the patient begins to walk about. Some, however, appear to carry the principle of pressure a little too far. The injured joint is put up in plaster-ofParis and kept in its casing for several weeks or even two or three months. This is going to the opposite extreme. The joint when set free is very stiff and of ten exceedingly weak.

I cannot do better than briefly describe the course I have adopted of late in severe sprains of the ankle. As soon as possible I cover the joint with a stiff starched bandage over a thick covering of wool. The limb is kept raised and at rest. At the end of a week I slit up the bandage examine the joint, and move it as far as it will go in all its movements. It is no uncommon thing then to find that almost all swelling has disappeared and that the movements are fairly good. If the injury is very severe I place the joint back in the original covering, apply over it a fresh bandage, and have that starched. This at the end of another week is again slit up and the joint moved about freely. In slighter cases I re-apply the old cover and simply put a bandage over it. This is undone every day and the joint well worked. When from ten to fourteen days have elapsed from the date of the injury I allow the patient to begin to walk, and the distance covered is increased every day. After three weeks I make the patient use a well-known orthopædic exercise which consists of alternate flexion and extension of the ankle joint with rotation of the foot. It is no uncommon thing to have such a case practically well in a month and abcolutely free from stiffness and weakness in six weeks. There is no tendency to relapse. For a severe sprain of the ackle sucb a result is satisfactory.

Koowsley.

\section{ISOLATION IN SCARLET FEVER UNNECES.} SARY AND INEXPEDIENT.

\section{BY ARTHUR WIGIESWORTH, L.R.C.P. LOND,} M.R.C.S ENG., L.S.A.

I HAVE on several occasions called your attention to the great value of carbolic acid in the treatment of scarlet fever, for in $\mathrm{my}$ hands it has proved a specific for that hitherto much dreaded zymotic disease. Without troubling you again with details I may summarise the results by stating that if saw my patients in the initial stage of the disease they all recovered; that I have had only three cases of albuminuria all transient in duration; only one of glandular suppuration and all other usual sequelæ have been characteristically absent. Finally, all the patients have recovered in a remarkably short space of time and with but little enfeeblement of strength. This treatment consists in administering to all patients, so soon as scarlet fever is sus pected or diagnosed, from one to six grains of carbolic acid (according to age) freely diluted with water and continuing it every two hours until the rash has finally disappeared, and then reducing the dose and frequency of administration until convalescence has been fully established. This practice I have pursued for over sixteen years and each succeeding year confirms my opinion of its inestimable value.

The subject of this paper has, however, only recently forced itself upon my attention, and was chiefly due to a perusal of Flügge's work on Micro-organisms, which has given me a scientific basis to work upon. It is to this scientific

1 The above paper was read before the Liverpool Medical Snciet nearly four years ago. Subsequent experience has amply confirmed these views so far as practical observation can demonstrate their truth Considering the rapid multiplication of bacteria, as stated by Cohn, it is imperative that the administration of the acid should commence immediately on the outset of symptoms leading even to a suspicion of (The complete surcess of the treatment will depend on strict observance of this rule.-A. W. 